\title{
Personnel Management: Needs-oriented Recruitment Planning in Organizational Development
}

\author{
Bianca Laiu ${ }^{1}$, Sara Voicu ${ }^{1}$ \\ ${ }^{1}$ Faculty of Sociology and Social Work, Babeş-Bolyai University, Romania
}

\begin{abstract}
This article aims to discuss personnel management in terms of needs-oriented recruitment planning aspects in organizational development. The determinant of the success of a company is human or labor. Even labor provides the largest contribution to the success of a company compared to other factors such as capital, raw materials or machinery. However, not all workers can become productive workers. This workforce must be selected, placed, trained and assessed for their achievements and given appreciation for every achievement that they have contributed to the company. If the conditions of a company allow it to provide benefits or insurance to each of its workers, this will increase the workforce productivity. During its development, the company will face increasingly complex manpower problems, thus human resource management must be carried out professionally by a separate department within a company, namely the Human Resource Department. Human Resource Management or better known as Personnel Management is management that specializes in the field of personnel or in staffing.
\end{abstract}

Keywords: Human Resource Department, Human Resource Management, Company

Received: December 20, 2020

Revised: December 26, 2020

Accepted: January 2, 2021

\section{Introduction}

In general, Personnel Management has more advisory powers than leadership powers. In this case, the Personnel Department helps other departments within a company to provide, train and advance the workforce in serving each of these departments. Seeing the importance of the role of human resources in a company, it can be said that humans are the most important asset that has an impact on the welfare of a company. Personnel management is a science that studies how to provide facilities for development, work and also a sense of work participation in an activity or activity.

According to Klingner et.al (2015) personnel management is the art of being able to carry out, among others, planning, organizing, monitoring, so that the effectiveness and efficiency of personnel can be increased as much as possible in achieving goals. Personnel Management is "planning, organizing, directing and controlling labor procurement, development, compensation, integration, maintenance, and termination of employment with human resources to achieve individual, organizational, and community goals." The objectives of personnel management relate to the objectives of the company in general. This is because the company's management strives to be able to create efficiency in the field of labor, namely as profit efficiency and continuity. This personnel management involves an effort to be able to create conditions in which each employee is encouraged to be able to provide the best possible contribution to his superior, because he cannot expect maximum efficiency without the full cooperation of its members.

\section{Human Resource Planning}

The purpose of human resource planning is to create all synergies between the company and the conditions of available human resources or in other words, with human resource planning, 
human resource activities will always be consistent with the direction or goals of the company.

In preparing human resource planning, management needs to make an environmental analysis and organizational assessment. Environmental analysis is intended so that management can anticipate changes that may occur in the future. In general, the factors that cause these environmental changes are technological advances, government regulations, economic instability, productivity crises, increased employee education and population redistribution (Wang et al., 2018).

The environment that can affect the availability of labor can be explained as follows: (a) Economic Environment. This environment can influence spending levels, risk and spending priorities. High inflation rate, monetary crisis can cause companies to be more careful in spending. Here the company may reduce funds for training, education, improvement of work safety or even for wages and benefits for employees. (b) Social environment. In this case, habits, sub-culture or population trends can affect the organization. Managers need to understand the social environment in which the company operates, because this will affect the relationship between workers and management. Attitudes, social values and beliefs can influence what workers expect in the organization. (c) Political Environment. This environment concerns the government's attitude towards companies, labor regulations, and social welfare. Government regulations that require companies to provide health benefits, provide pension funds or insure workers will cause companies to try to implement them. (d) Legal Environment. Progress in the field of law provides protection for workers to get their rights and obligations proportionally. The law also places workers in the same position, there is no difference, from the highest level of managers to the lowest employees. (e) Worker Environment. This environment describes the attitude of employees and society towards the union. Highly educated employees will react negatively to unions compared to workers with low levels of education. (f) Technology Environment. Here, technology will affect the skills required of workers and the work tools needed to complete a job. For example, an automobile or aircraft assembly industry requires a skilled workforce, so this affects the recruitment, selection and training of employees

\section{Job Analysis and Design}

Analysis and design of the company is prepared with the intention of examining a job, conditions and the environment in which the work is carried out. A job is composed of a set of tasks, assignments, obligations and responsibilities. Job analysis is a determination through observation, study and information relating to the nature of a particular job. So it can be concluded that, job analysis is the process of collecting and examining the main work activities in a position and the qualifications needed to carry out these activities. So it can be said that job analysis is the process of collecting and examining the main work activities of a position and the qualifications needed to carry out these activities (Colombini, 2002; Parker, 2015).

From the point of view of the personnel department, the objectives of preparing a job analysis (job analysis) are : (a) Identify activities undertaken (b) Evaluating workplaces related to work (c) Determine the terms of employment for employees (d) Identify information about operational procedures (e) Describe the limits of authority and responsibility. Job analysis can help in communicating the expectations of a job to incumbents, supervisors and colleagues. By observing existing job descriptions, employees can more quickly learn the scope and limitations of their responsibilities.

\section{Job Description}


Defined by Mader-Clark (2013) a job description is a written description of what an employee must do in a particular job. From the job analysis, it is then described in a job description, so the writing is descriptive in nature and consists of notes on existing and related job facts. So a job description is a document that provides information about job obligations, duties and responsibilities.

A job specification describes the skills of a person and this is used as a requirement for hiring. So a job description determines whether the job is a job profile, whereas a job specification describes what the job demands of the employee. Here job specifications emphasize more on physical equipment, knowledge, experience, mobility and physiological abilities as well as intelligence required in carrying out tasks and responsibilities.

\section{Job Evaluation}

Job evaluation is an activity of comparing a particular job with another job to ensure that the job is rewarded fairly. The method often used in job evaluation is to break down the work into identifiable parts and then assign a value / weight to each part. Each job in the company is then evaluated according to these components. The factors assessed are generally skills, responsibility, initiative, loyalty / loyalty, discipline and work environment (Spyridakos et.al, 2001).

\section{Job Design (Job Evaluation)}

Stated by Mader-Clark (2013) job design is the process of determining the tasks to be carried out, the techniques that will be used to carry out these tasks and how the work is with other jobs in the company. So, job design seeks to integrate tasks, functions and relationships (job content), remuneration (compensation) and the qualifications of workers required for each job. Job design techniques can influence the level of specialization and psychological dimensions of the job. In this case there are 4 job designs : (1) Job simplification. This technique leads to highly specialized jobs. In simplification of this job, it is intended that employees who are less trained, can do this job well. (2) job rotation. Here employees are transferred from one job to another with the intention of mastering various fields of work, reducing boredom and making employees more flexible in accepting various types of work. (3) Job expansion (job enlargement). This expansion or expansion of work is the opposite of job simplification. Here the work is extended to the degree that a meaningful part is completed by an employee. Employees get some variety in work so it is hoped that it can reduce boredom.(4) job enrichment. These programs can generally give workers more authority to plan work as well as give them the freedom to decide how the work is done. It is hoped that this job enrichment can further increase job responsibilities.

\section{Withdrawal of Labor (Recruitment)}

Before an organization pulls out a workforce, the first step is to forecast the need for labor in the short term. This can be done to find information about the work load (work lood) and the work force (work force). Work load analysis and work force analysis can accurately determine the quantity and quality of labor required.

First, the identification of employee work hours required to complete a certain workload within a certain time. The number of hours worked per employee will indicate the number of employees required. Then a labor force analysis is carried out, namely the process of determining the number of workers needed to complete certain jobs so that the balance of the company can be maintained normally. Factors that need to be considered in determining the number of workers are the level of absenteeism and labor turnover. A high level of 
absenteeism indicates a high number of employees who do not come to work (Lilly \& Coyte, 2007).

Companies must strive to reduce the high level of absenteeism, because the more employees who do not enter (even if they do not enter they are also not paid), it will interfere with the company's work schedule so that work completion can be delayed and product quality can decrease because they are done in pursuit of targets. Companies also need to carry out an analysis of employee turnover (labor turnover) to ensure the availability of a sufficient number of workers. Turnover of labor is the flow of employees into and out of the company. This turnover is an indication of employee stability in the company. The higher the turnover, the more employee turnover occurs.

\section{Labor Selection}

If the withdrawal process has succeeded in providing potential workforce candidates, the selection process is an activity to select from a group of applicants who best meet the selection criteria to be placed in positions that require them. This selection process begins when the applicant sends an application letter or comes directly to the company and ends when the decision is made. The following are the types of tests in labor selection: (a) Intelligence test. This type of test is the most widely used, namely to determine a person's ability to think thoroughly and logically. (b) Talent test (Attitude test). With this test, it will be tried to measure whether a person has the hidden ability to learn a job if he is given enough practice. (c) Achievement Test (Achivement test). This test measures the participants' current abilities. So this test tests how much the participants know about something. (d) Interest test. With this test it is known that a person's interest in a particular job or position. If he is interested in a particular job, then he will do better than those who are less interested. (e) Personality test. A person's personality greatly determines the success of that person in pursuing a career or completing his tasks. This test observes how the prospective worker interacts, behaves and cooperates with others (Faia, \& Merkl, 2014).

\section{Orientation of Training and Workforce Development}

After the workforce is accepted or passes the selection, the next stage of the workforce will carry out orientation and induction. Orientation is an activity to introduce the workforce / company, regarding its functions, duties and personnel. Then after that the induction stage is also carried out. Induction is an activity for new employees to study the company's history, organizational structure, types of products produced, labor regulations, compensation and benefits as well as employees involved in the company. At this stage of induction and orientation, the expectations of the employees and the expectations of the organization interact with each other so that there will be harmony and ultimately will be able to form satisfaction on each party.

Managers are increasingly aware of the importance of training and workforce development, this is increasingly realizing that corporate organizations cannot be separated from their environment which is changing all the time. Company organizations can live (survival) by using opportunities or overcoming challenges from a complex environment, so the consequence is that the company organization will always face changes in it. More specifically, they will invest so that members of the company organization (workforce) can adjust to the changes that are always happening. Therefore, managers will increasingly realize that training and development (to adapt and develop) is a continuous or continuous process. In more detail, these changes can be divided into: (a) Changes in company organizational goals. Changes in goals can be caused by a rapidly changing organizational environment. If there is no change (adjustment / development) in goals, what will happen is 
stagnation or stagnation, a process that can even lead to death or destruction. (b) Changes in the factors that affect the achievement of company organizational goals. Various factors such as economic resources, the implementation of the company's operational functions, even the specific environment of each of these functions will determine and influence the achievement of company goals (Roche, 2001)

Various changes that occur in the company: (1) Changes in production. Demand for a good can go up or down if it is caused by various factors such as population growth, change in taste, substitute goods, fashion and so on. (2) Technology changes. In connection with technological changes, the process of manufacturing goods will easily become out of date and less efficient. (3) Change of employees. Before they can carry out their duties, new employees generally have to be trained so that they can quickly adjust to changes. (4) Changes in the company's organizational environment: (a) Government laws and regulations. Specifically here are changes to laws and regulations on labor relations. (b) Political changes both nationally and internationally. For example, changes in government policies, relations with the European Economic Community (EEC) and ASEAN.

\section{Training and Development Needs}

Three levels of training and development requirements within the company organization: (1) Needs at the organizational level (organizational needs). At this stage, the identification of training needs will highlight places or organizations that really need training and organizational analysis so that in organizational analysis the main questions must be answered, where is training really needed? or in which section / section / job group is training required? (2) Needs at the position level (occupational need). To reveal the need for training at this level, a job analysis or job analysis is used. In the analysis of this position, it must be answered what skills, knowledge, or attitudes are required to occupy a certain position so that various jobs or tasks can be carried out in the position or job specification. (3) Needs at the individual level (individual need). To express needs and training at this level an analysis called an assessment or specification is used individually. So, after the needs at the organizational level and the needs at the position level have been obtained, then it is determined who will need training and in what matters. Employee performance is the level at which the employee achieves the job requirements. This job appraisal includes both qualitative and quantitative aspects of the work implementation. The benefits of this performance appraisal are first, providing information that can assist in decisions relating to issues of promotion, salary increases, transfers or layoffs. The second benefit is that it can be used to encourage employee development. Requirements for better assessment. Every superior must know the duties and jobs of his subordinates

\section{Compensation}

Companies can reward employees in financial and non-financial forms. Financial rewards include the provision of salaries / wages, allowances, insurance guarantees, distribution of bonus benefits and pensions. Meanwhile, financial awards include good working conditions, awards or achievements (Frey, 2007). Compensation can mean different things to different people, depending on the perspective of each. As employees indicate compensation in return for work that the employee has completed and other employees may perceive compensation as the value the company attaches to the employee's skills or abilities. In this case the meaning of compensation is broader than the definition of salary / wage. Compensation can be defined as all forms of financial return and benefits obtained by employees as part of an employment relationship. Compensation includes monetary (extrinsic) rewards and organizational intrinsic rewards (recognition, provision of opportunities for promotion, challenges of employment opportunities) 
Meanwhile, the meaning of wages, according to Edwin B. Flippo, is the price for services that have been provided by one person to another. From this understanding, it can be said that wages can be a substitute for services that have been rendered by workers to other parties or companies where they work. The purpose of providing compensation : (1) Attract employees to work (2) Hold back employees from changing jobs (3) Provide work motivation. Intrinsic Rewards and Extrinsic Rewards, there are two categories of compensation in giving compensation: (a) Intrinsic reward. This type of reward is derived from the individual himself. For example, personal satisfaction for the success of completing a job well. (b) Extrinsic rewards. These rewards come from outside that are given to the workforce to influence their behavior and performance. For example, wages, bonuses, profit sharing (financial).

\section{Maintenance of workforce}

The manager as a motivator must be good at giving directions so that this gap can be reduced or eliminated, so that in this case an operational function is needed, namely retaining employees.

\section{Definition of Maintaining Employee Conditions}

Basically, the function of maintaining employee conditions does not only mean preventing the departure of employees who have been withdrawn / accepted by the company, but wider than that. In this capable and cooperative condition, the company should maintain the cooperative attitude and work skills of the employees. Based on the conditions owned by the employees, the company's activities or programs can be divided into two, namely: (a) To maintain the physical condition of employees, occupational safety and health programs can be prepared. (b) To maintain a cooperative attitude, service programs can be prepared in several / various forms of activities (service programs).

\section{Occupational Health and Safety Program}

Historically, the human view of occupational safety and health has evolved from a simple one to one based on the concept of complex systems. In detail, these views are as follows: (a) The fate factor of the employees being hit by an accident. At this time there is no rational effort to prevent accidents from happening again. (b) Physical environmental factors of employees, such as machines, buildings, rooms, equipment. During this period, preventive efforts were more focused on installing facilities which protect, control and prevent accidents. (c) Human negligence factors, such as being careless, sleepy, drunk or unable to carry out tasks / jobs. (d) The mismatch factor combination of factors managed in the company.

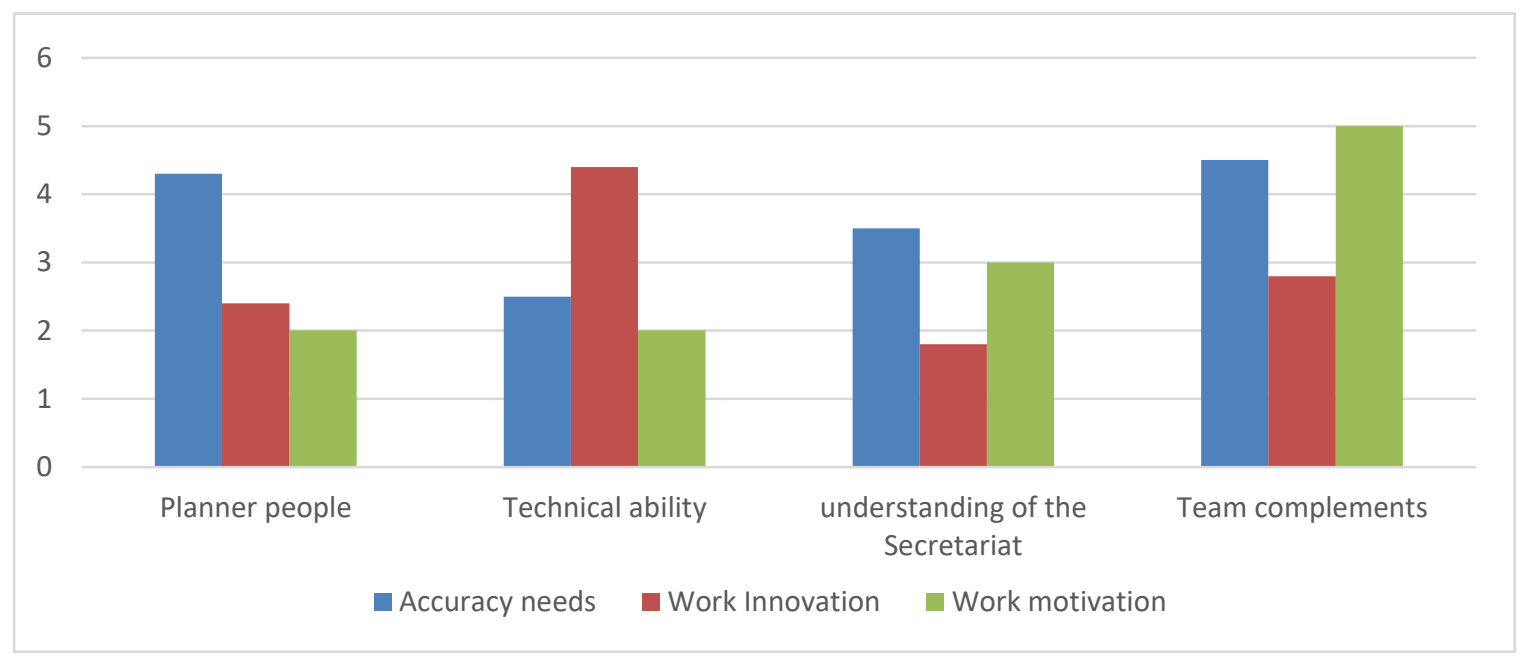


Figure 1. Accuracy in requirements

Accuracy in requirements is needed to work closely with multitasking, insisting on completing more than one task simultaneously can actually waste valuable time rather than useful. Research has shown that people who try to do two or more activities at once become easily distracted, and the quality of their work is poor. The key is to focus on completing one task at a time before moving on to projects.

Technical ability is part of the skill set required for a job. Hard skill is a skill required for an individual to successfully do a job. Hard skills can be obtained through formal education and training programs, including lectures, internships, short-term training classes, online courses and certification programs, as well as on-the-job training. However, if you only have hard skills, your business will not be successful, so you need employees who have other skills, such as soft skills that contribute to customer satisfaction.

\section{Conclusion}

From the discussion above we can conclude that an effort to be able to create conditions in which each employee is encouraged to be able to provide the best possible contribution to his superior is called by personnel management that include human resourches,job description, evaluation, and design. Personnel management also discussed about he purpose of industrial relations is to create industrial relations that are harmonious, dynamic, conducive and just in the company. There are three elements that support the achievement of the objectives of industrial relations, namely rights and obligations that are guaranteed and implemented. If a dispute arises, it can be resolved internally / bipartite. Work strikes by workers and company closures (lock outs) by employers, do not need to be used to impose their respective will, because the disputes that have occurred have been resolved properly. The mental and social attitudes of employers and workers are also very influential in achieving the success of our expected industrial relations goals.

\section{References}

Colombini, D. (2002). Risk Assessment and Management of Repetitive Movements and Exertions of Upper Limbs: Job Analysis, Ocra Risk Indicies, Prevention Strategies and Design Principles. Elsevier.

Faia, E., Lechthaler, W., \& Merkl, C. (2014). Labor selection, turnover costs, and optimal monetary policy. Journal of Money, Credit and Banking, 46(1), 115-144.

Frey, B. S. (2007). Awards as compensation. European Management Review, 4(1), 6-14.

Klingner, D., Llorens, J. J., \& Nalbandian, J. (2015). Public personnel management. Routledge.

Lilly, M. B., Laporte, A., \& Coyte, P. C. (2007). Labor market work and home care's unpaid caregivers: a systematic review of labor force participation rates, predictors of labor market withdrawal, and hours of work. The Milbank Quarterly, 85(4), 641-690.

Mader-Clark, M. (2013). The job description handbook. Nolo.

Parker, S. K. (2015). Job design. Wiley Encyclopedia of Management, 1-5.

Roche, A. (2001). What is this thing called workforce development. Systems, settings, people: Workforce development challenges for the alcohol and other drugs field. Adelaide: National Centre for Education and Training on Addiction, 5-22. 
Spyridakos, A., Siskos, Y., Yannacopoulos, D., \& Skouris, A. (2001). Multicriteria job evaluation for large organizations. European Journal of Operational Research, 130(2), 375-387.

Wang, S., Li, J., \& Zhao, D. (2018). Institutional pressures and environmental management practices: The moderating effects of environmental commitment and resource availability. Business Strategy and the Environment, 27(1), 52-69. 